\title{
UNA APROXIMACIÓN A LA TEMÁTICA DE LOS SEGUROS EN EL CONTEXTO DE LA EXPLOTACIÓN Y EXPLORACIÓN DE HIDROCARBUROS COSTA AFUERA*
}

\section{AN APPROACH TO THE TOPIC OF INSURANCE IN THE CONTEXT OF THE EXPLORATION AND EXPLOITATION OF HYDROCARBONS OFFSHORE}

\author{
Andrea Signorino Barbat** \\ Fecha de recepción: 12 de septiembre de 2016 \\ Fecha de Aceptación: 30 de noviembre de 2016 \\ Disponible en línea: 30 de diciembre de 2016
}

\section{Para Citar este articulo/To cite this article}

Signorino Barbat, Andrea, Una aproximación a la temática de los seguros en el contexto de la explotación y exploración de hidrocarburos costa afuera, 45 Rev.Ibero-Latinoam.Seguros, 185-230 (2016). http://dx.doi.org/10.11144/Javeriana.ris45.uats

doi:10.11144/Javeriana.ris44.uats

* Artículo de reflexión

** Doctora en Derecho y Ciencias Sociales, Traductora Pública, Universidad de la República Oriental del Uruguay. Postgrado en Gerencia y Habilidades gerenciales, Universidad ORT. Presidente de CILA- Comité Ibero-Latinoamericano de AIDA (Association Internationale du Droit des Assurances), Presidente AIDA-Uruguay, Presidente Grupo internacional Nuevas Tecnologías, Prevención y Seguros en CILA, Vicepresidente Grupo internacional Protección del consumidor y seguros en AIDA- Miembro Comisión Directiva de la Asociación uruguaya de derecho marítimo. Miembro del Instituto Ibero-latinoamericano de derecho marítimo. Asesora legal experta en seguros y reaseguros, Profesora de grado y postgrado en seguros en Argentina, Brasil, Colombia y Uruguay. asignorino@netgate.com.uy -www.andreasignorino.com.uy 


\section{RESUMEN}

Sin dudas la exploración y explotación de hidrocarburos costa afuera supone grandes desafíos en la prevención de riesgos que pueden ocurrir en dicho contexto. La pregunta es qué respuesta le puede dar el seguro a estos riesgos y cuáles deberían ser los aspectos a tener en cuenta en este sentido, sobretodo en Uruguay donde este tema es incipiente.

Palabras clave: exploración; explotación; hidrocarburos; petróleo; costa afuera; seguros.

\section{ABSTRACT}

Undoubtedly, the exploration and exploitation of hydrocarbons offshore means great challenges in preventing risks that could arrive in this context. The question is what can of answer to these risks could give the insurance and what should be the aspects to consider in this regard, especially in Uruguay where this issue is emerging.

Key words: Exploration; exploitation; hydrocarbons; oil; offshore; insurance.

\section{SUMARIO}

1. INTRODUCCIÓN Y ANTECEDENTES GENERALES. 2. ANTECEDENTES EN EL URUGUAY. 3. PANORAMA ACTUAL. 4. LOS SEGUROS EN EL CONTEXTO DE LA EXPLOTACIÓN Y EXPLORACIÓN OFFSHORE DE HidROCARBUROS. 4.1. VigenCIA DEL TEMA. 4.2. LOS SEgUROS EN LA PLATAFORMA CONTINENTAL Y LA RESERVA DE MERCADO EN MATERIA ASEGURADORA. 4.3. El CONCEPTO DE TERRITORIO 4.3.1. ¿Y qué significa ampliar la plataforma continental? 4.3.2. Concluyendo respecto al territorio. 4.3.3- Soberanía y derechos de soberanía sobre el territorio. 4.4. CONCLUYENDO SOBRE LA RESERVA DE MERCADO EN LA PLATAFORMA CONTINENTAL. 5. LOS SEGUROS EXIGIDOS CONTRACTUALMENTE EN EL MARCO DE LA EXPLORACIÓN Y EXPLOTACIÓN OFFSHORE. 5.1. RESPONSABILIDAD del contratista y subcontratista. 5.2. Aspectos preventivos. 5.3. Tipos de Seguros. 5. CONCLUSIONES. 


\section{INTRODUCCIÓN Y ANTECEDENTES GENERALES}

Se dice que la exploración mar adentro inició a finales del siglo XIX en la costa pacífica de E.E.U.U, en aguas someras.

Después de la Segunda Guerra Mundial, las tecnologías mejoraron notablemente, permitiendo que la exploración pasara a áreas profundas. Esto plantea los primeros interrogantes legales, dado que la exploración y explotación se traslada de las zonas costeras, inclusive más allá del mar territorial. ${ }^{1}$

El presidente Truman, en EE UU, hizo una declaración en la que consideró que los países tienen derecho a explorar más allá del mar territorial, en la plataforma continental. Esta declaración se entendió como la teoría de la prolongación ${ }^{2}$, respaldada por la Corte Internacional de Justicia, que en la decisión sobre la Placa Continental del Mar del Norte consideró que el Estado costero tiene derecho a explotar en el área de la placa continental que se entiende como una prolongación natural de su territorio bajo el mar, debido al principio de soberanía ${ }^{3}$.

En los últimos años, debido a los grandes avances tecnológicos, la exploración y explotación en el mar está creciendo y también los desafíos que la misma presenta a un marco legal que no está preparado para los avances de la ciencia.

De esto no escapan los seguros, que plantean su propia problemática, sobretodo, aunque no únicamente, en cuanto al alcance de la normativa nacional aplicable y las coberturas exigibles.

\section{ANTECEDENTES EN EL URUGUAY}

Desde hace años en la República Oriental del Uruguay se habla de la existencia de petróleo en su "costa afuera", veremos luego el alcance de este concepto.

1 Dra Liliana Rodríguez “Aspectos legales de la exploración de hidrocarburos mar adentro” 12/03/2014 www.rodriguezretamoso.co.uk, Recuperado 5 julio 2016.

2 Proclamación Presidencial de los EE UU No 2667, política de los EE UU con relación a los recursos naturales en el subsuelo y la placa continental, Washington, 28 de Septiembre de 1945.

3 Decisión de la Corte Internacional de Justicia, en la Sentencia sobre la Placa Continental del Mar del Norte. (North Sea Continental Shelf, Judgment, I.C.J. Reports 1969, p. 3). 
No obstante ello, el tema ha tenido nuevos ímpetus en los últimos años con los contratos de exploración y explotación de hidrocarburos firmados por el ente estatal uruguayo ANCAP (Administración nacional de Alcohol y Portland) con diversas empresas petroleras extranjeras interesadas en la exploración y explotación de hidrocarburos costa afuera , comúnmente conocida como explotación y exploración "offshore".

En la resolución sin número del Ministerio de Industria, Energía y Minería publicada en el Diario oficial el 17 de setiembre de 2012, se aprueba el "Modelo de Contrato para el

Otorgamiento de Áreas para la Exploración - Explotación de Hidrocarburos en Costa Afuera de la República Oriental del Uruguay", el cual originalmente figuraba como anexo a las "Bases Para la Selección de Empresas Petroleras para la Exploración y Explotación de Hidrocarburos en Costa Afuera de la República Oriental del Uruguay (Ronda Uruguay II)", aprobadas por Decreto del Poder Ejecutivo N³ 316/2011

En el marco de lo dispuesto en dichas Bases, ANCAP recibió distintas propuestas, para distintas Áreas para la Exploración - Explotación de Hidrocarburos en Costa Afuera.

Analizadas las propuestas por parte de ANCAP resultó que a la luz de los criterios establecidos en las Bases las ofertas con mayor puntaje por área fueron:

* Área 6, BP Exploration Operating Company,* Área 8, BG (Uruguay) S.A., * Área 9, BG (Uruguay) S.A.,Área 11, BP Explotation Operating Company, * Área 12, BP Exploration Operating Company, ${ }^{*}$ Área 13, BG (Uruguay) S.A., * Área 14, TOTAL E\&P ACTIVITES PETROLIERES, * Área 15, Tullow Oil PLC.

Finalmente tras la culminación del proceso de la llamada "Ronda Uruguay II", se suscribieron nueve contratos de exploración y explotación de hidrocarburos en la plataforma continental uruguaya y se obtuvieron resultados históricos de inversión en exploración de hidrocarburos para nuestro país, posicionándolo en un lugar destacado del mapa petrolero mundial.

Como resultado de este proceso, se obtuvo valiosa información que incrementa el conocimiento geológico y geofísico de nuestra cuenca. 
A efectos de continuar este proceso tendiente a incrementar el conocimiento de nuestros recursos hidrocarburíferos costa afuera ("offshore"), es que ANCAP y el Ministerio de Industria, Energía y Minería resolvieron llevar adelante la "Ronda Uruguay 3", proceso de características similares a los dos precedentes.

En tal sentido, Uruguay promocionó la Ronda Uruguay III en diversos eventos y ferias internacionales, tales como NAPE, APPEX, AAPG anual, EAGE anual en Ámsterdam, $21^{\circ}$ WPC en Moscú, AAPG Internacional en Estambul, entre otros, de modo de dar a conocer a la industria del upstream las características principales de la Ronda Uruguay 3.

Figura 1. Mapa de Áreas con contrato. Fte. ANCAP - www.ancap.com.uy



Como resultado de todas estas acciones, como expresamos, Uruguay firmó 9 contratos de Exploración y Producción, offshore, suscritos con empresas de primer nivel (3 contratos con BP, 3 con BG, 1 con Total, 1 con el consorcio formado por Tullow Oil e Inpex y uno con el consorcio formado por YPF, Shell y GALP). 
Los contratos correspondían a áreas localizadas en las 3 cuencas offshore, Cuenca Punta del Este, Cuenca Pelotas y Cuenca Oriental del Plata, las cuales varían desde aguas someras a aguas ultra profundas (ver Fig. 1).

La empresa Japonesa Inpex concretó un "farm-in" por un 30\% del área 15, correspondiente a Tullow Oil, con posterioridad a la suscripción del contrato entre ANCAP y esta última.

Petrobras concretó un "farm-out" de sus activos en Uruguay a la empresa Shell. El consorcio integrado por YPF, Shell y GALP devolvió el área 4 (una de las áreas adjudicadas en el marco de la Ronda Uruguay 2009), continuando sus trabajos en el área 3, siendo su operadora YPF.

A fines de 2015, todos los contratistas de la Ronda Uruguay II se enfrentaron a la decisión de devolver sus áreas o pasar al segundo período exploratorio, durante el cual debían comprometer la perforación de un pozo exploratorio si deseaban pasar al próximo período exploratorio.

FIgURA 2. Alcance de los contratos firmados-Fte ANCAP- www.ancap.com.uy

\begin{tabular}{|c|c|c|c|c|c|}
\hline $\begin{array}{l}\text { Empresa/ } \\
\text { Consorcio }\end{array}$ & Área & $\begin{array}{c}\text { Fecha de } \\
\text { suscripción } \\
\text { del contrato }\end{array}$ & $\begin{array}{c}\text { Tamaño } \\
\text { áreas } \\
\left(\mathrm{Km}^{2}\right)\end{array}$ & $\begin{array}{c}\text { Plazo 1er } \\
\text { período } \\
\text { exploratorio }\end{array}$ & $\begin{array}{c}\text { Trabajo exploratorio mínimo } \\
\text { comprometido }\end{array}$ \\
\hline $\begin{array}{l}\text { YPF/ } \\
\text { SHELL/ } \\
\text { GALP }\end{array}$ & 3 & $09 / 02 / 2010$ & 5.500 & 09/10/2014 & $\begin{array}{l}\text { Licenciamiento de la sísmica } \\
\text { 2D existente } \\
\text { Modelado geológico y geofísico } \\
\text { sobre la sísmica 2D existente }\end{array}$ \\
\hline BP & 6 & $05 / 10 / 2012$ & 6.960 & $03 / 12 / 2015$ & $\begin{array}{l}500 \mathrm{~km}^{2} \text { sísmica 3D } \\
3000 \mathrm{~km} \text { sísmica 2D }\end{array}$ \\
\hline BG & 8 & 05/10/2012 & 2.230 & $14 / 11 / 2015$ & $\begin{array}{l}2230 \mathrm{~km}^{2} \text { sísmica 3D } \\
2230 \mathrm{~km}^{2} \text { electromagnetismo 3D } \\
20 \text { muestras subsuelo marino } \\
3 \text { estudios adicionales } \\
\text { Procesamiento de datos sísmi- } \\
\text { cos por } 881 \text { UT1 } \\
\text { Compra de información por } \\
\text { más de } 450 \text { UT }\end{array}$ \\
\hline
\end{tabular}




\begin{tabular}{|c|c|c|c|c|c|}
\hline BG & 9 & 05/10/2012 & 3.290 & $14 / 11 / 2015$ & $\begin{array}{l}3290 \mathrm{~km}^{2} \text { sísmica 3D } \\
3290 \mathrm{~km}^{2} \text { electromagnetismo 3D } \\
20 \text { muestras de subsuelo marino } \\
3 \text { estudios adicionales } \\
\text { Procesamiento de datos sísmi- } \\
\text { cos por } 881 \text { UT } \\
\text { Compra de información por } \\
\text { más de } 450 \text { UT }\end{array}$ \\
\hline BP & 11 & 05/10/2012 & 8.325 & $03 / 12 / 2015$ & $2000 \mathrm{~km}^{2}$ sísmica 3D \\
\hline BP & 12 & 05/10/2012 & 10.670 & $03 / 12 / 2015$ & $10670 \mathrm{~km}^{2}$ sísmica 3D \\
\hline BG & 13 & 05/10/2012 & 7.560 & $14 / 11 / 2015$ & $\begin{array}{l}7560 \mathrm{~km}^{2} \text { sísmica 3D } \\
7560 \mathrm{~km}^{2} \text { electromagnetismo 3D } \\
40 \text { muestras de subsuelo marino } \\
3 \text { estudios adicionales } \\
\text { Procesamiento de datos sísmi- } \\
\text { cos por } 504 \text { UT } \\
\text { Compra de información por } \\
\text { más de } 120 \text { UT }\end{array}$ \\
\hline Total & 14 & 05/10/2012 & 6.690 & $27 / 03 / 2016$ & $\begin{array}{l}1 \text { pozo exploratorio } \\
6690 \mathrm{~km}^{2} \text { sísmica } 3 \mathrm{D} \\
50 \text { muestras de subsuelo marino } \\
3 \text { estudios adicionales } \\
\text { Procesamiento de datos sísmi- } \\
\text { cos por } 34 \text { UT } \\
\text { Compra de información por } \\
\text { más de } 120 \text { UT }\end{array}$ \\
\hline $\begin{array}{l}\text { Tullow } \\
\text { Oil / } \\
\text { Inpex }\end{array}$ & 15 & 05/10/2012 & 8.030 & $16 / 12 / 2015$ & $\begin{array}{l}300 \mathrm{~km}^{2} \text { sísmica } 3 \mathrm{D} \\
1 \text { estudio adicional } \\
\text { Procesamiento de datos sísmi- } \\
\text { cos por } 255 \text { UT } \\
\text { Compra de información por } \\
\text { más de } 120 \text { UT }\end{array}$ \\
\hline
\end{tabular}




\section{PANORAMA ACTUAL}

A pesar de las alentadoras perspectivas, lo cierto es que el derrumbe del precio del crudo provocó el abandono de la exploración de alto riesgo en el mar por parte de las grandes petroleras del mundo, aunque la francesa Total encontró una "ventana de oportunidad" para realizar la perforación que se comprometió por contrato ante ANCAP. Los precios de las compañías de logística y servicios de perforaciones cayeron abruptamente producto de una capacidad ociosa en ascenso.

Además de Total, siguen adelante Shell que tiene tres bloques, la irlandesa Tullow Oil y la japonesa Inpex, entre otros. La inglesa BP entregó el año pasado sus tres bloques en la plataforma marítima.

El emprendimiento es compartido por varias de las empresas líderes mundiales en el negocio. La noruega Statoil adquirió un 15\% del proyecto de la francesa Total. ExxonMobil había adquirido otro 35\% en noviembre de 2015 del proyecto de Total. Estas iniciaron el 30 de marzo de 2016, las operaciones de perforación exploratoria en el pozo Raya-1, localizado en el block 14 de la plataforma offshore (marítima) uruguaya. ${ }^{4}$

Uruguay volvió así a soñar con la posibilidad de sumarse al club de los productores del oro negro, luego de un intento frustrado en mar hace cuarenta años. Se estimó en marzo que en un plazo de 100 días, el país sabría si la perforación es exitosa. De todas formas, la coyuntura actual de la industria petrolera y los tiempos de ese negocio, llevan a ser cautos para proyectar un beneficio económico en el corto plazo.

Este primer pozo exploratorio en busca de hidrocarburos es perforado en aguas ultra profundas de Uruguay a más de 3.400 metros. Una vez finalizado, el Raya-1 superará el récord actual de lámina de agua en perforación en aguas profundas.

El procedimiento incluye la cimentación de cada metro que se avanza, de manera tal que la estructura civil garantice la seguridad para los trabajadores y técnicos empleados en la exploración. El proceso culminará

4 El bloque 14, que cubre un área de 6,990 kilómetros cuadrados, se ubica a 250 kilómetros de distancia de la costa de Uruguay (400 kilómetros de Montevideo). Los socios del Raya-1 contrataron el buque perforador Maersk Venturer para llevar adelante las operaciones. 
con pruebas científicas concretas, a partir de la cual la empresa tomará mediciones para conocer si existen reservas comercializables.

Además, las empresas indicaron que el principal foco de atención para todos los equipos de operaciones involucrados es la seguridad de las operaciones, que incluye un extenso programa de preparación que se ha desarrollado con el contratista para la perforación.

En caso que el yacimiento sea comercialmente rentable, en una etapa posterior se deberán realizar entre 18 y 30 pozos adicionales dentro del bloque. La inversión en caso de que la presencia sea mayormente de crudo puede rondar los US\$ 6 mil millones y US\$ 20 mil millones en caso que predomine el gas. Ese período de análisis puede demandar entre tres y cuatro años, antes de iniciar la fase comercial.

En tanto, en una hipótesis más pesimista -que implicaría que la perforación de Total y ExxonMobil sea negativa, estaremos muy cerca de que la búsqueda de petróleo en la plataforma marítima uruguaya llegue a su fin.

\section{LOS SEGUROS EN EL CONTEXTO DE LA EXPLOTACIÓN Y EXPLORACIÓN OFFSHORE DE HIDROCARBUROS}

\subsection{Vigencia del tema}

Esta introducción sobre las perspectivas de la explotación y exploración offshore en nuestro país, podría sugerir la pérdida de interés en el estudio de los seguros en el marco de estas actividades.

No obstante, eso significaría un análisis netamente localista, que podría ser aplicable al Uruguay en el caso en que no resulte positiva la búsqueda de petróleo pero que del punto de vista de la investigación académica, no perdería vigencia si se tiene en cuenta solamente Latinoamérica, por quedarnos en nuestro continente.

Por ejemplo, es notoria la preocupación actual de Colombia por estas actividades y los riesgos implicados, por citar solo uno de los recientes países con emprendimientos de este tipo. ${ }^{5}$

5 La Agencia Nacional de Hidrocarburos (ANH) lanzó en marzo de 2014 la Ronda Colombia 2014, con un proceso de promoción internacional en Calgary, Houston, Londres y Yakarta para la exploración de 
Siendo el tema seguros una materia con bases comunes técnicas y jurídicas, que supera los análisis nacionales, es absolutamente válido aprovechar la ocasión que este tema esté en el tapete nacional para comenzar a analizar la temática e implicancias de los seguros en los riesgos ínsitos en estas actividades.

\subsection{Los seguros en la plataforma continental y la reserva de mercado en materia aseguradora}

A efectos de ubicar el tema, debemos antes que nada preguntarnos qué novedades arroja la circunstancia que las actividades de exploración y explotación offshore se desarrollen en la plataforma continental de un país y no en su territorio terrestre.

Esto en materia aseguradora merece una mayor consideración ya que debe analizarse la aplicación del principio de territorialidad que determina la reserva de mercado que rige en materia aseguradora.

Sabido es que muchos de los países de la región, y es notoriamente el caso de Uruguay, consagran en materia de seguros, una reserva de mercado basada en el principio de territorialidad. Eso significa que los riesgos que acaecen en el territorio nacional deben ser cubiertos por empresas aseguradoras debidamente instaladas, autorizadas y habilitadas a operar en el país. Esto es lo que en Uruguay consagra el artículo 2 de la ley 16.426 de octubre de 1993, conocida como Ley de desmonopolización del mercado asegurador.

Esta reserva cuenta con escasas excepciones, fruto de leyes posteriores aclaratorias y modificativas, en virtud de las cuales las únicas excepciones son los seguros de las mercaderías transportadas en el marco del transporte internacional y los seguros de los buques mercantes y de toda construcción flotante, autopropulsada o no, de carácter civil, salvo los buques de la flota pesquera nacional. ${ }^{6}$

yacimientos no convencionales de hidrocarburos en el Caribe y el Pacífico. El país busca más de 2,6 billones de dólares, con el fin de mantener la tendencia de inversión en el sector de los últimos años.

6 La Ley 16.426 en su art 2, luego de consagrar la mencionada reserva de mercado, en su inciso final en su texto original establecía: "Quedan exceptuados de lo dispuesto en el presente artículo los seguros relativos al transporte y comercio internacionales."

Luego la ley 16.851 de 2 de julio de 1997, estableció en su artículo $1^{\circ}$ : "Declárase, por vía interpretativa, que la excepción contenida en el inciso final del Artículo $2^{\circ}$ de la Ley 16.426, de 14 de 
Surge pues una primera cuestión relativa a si los seguros a contratar en el marco de la explotación y exploración de hidrocarburos costa afuera, deben o no ser contratados con empresas debidamente instaladas y autorizadas a operar en el país (no contratarlos en el extranjero), dado que dichas actividades ocurren y los riesgos implícitos en ellas pueden acaecer, en la plataforma continental (ergo, marítima).

Expresa el artículo 2 de la ley 16.426 en los párrafos que nos interesan a estos efectos (destacado es nuestro):

Artículo $2^{\circ}$. - Las empresas públicas o privadas para desarrollar actividad aseguradora deberán instalarse en el país y ser autorizadas por el Poder Ejecutivo, con el asesoramiento de la Superintendencia de Seguros y Reaseguros que se crea por la presente ley.

Las compañias reaseguradoras para instalarse en el país como tales deberán también contar con la previa autorización del Poder Ejecutivo.

Sin perjuicio de lo dispuesto por acuerdos internacionales celebrados por la República, el contrato de seguros, que contemple riesgos que puedan acaecer en su territorio, estará sujeto a todas sus normas legales, reglamentarias y fiscales y sólo podrá ser otorgado por empresas autorizadas conforme al inciso anterior.

octubre de 1993, refiere exclusivamente a la mercadería transportada". Y en su artículo $2^{\circ}$ : Agrégase al Artículo $2^{\circ}$ de la Ley 16.426, 14 de octubre de 1993, el siguiente inciso: "Los vehículos o medios utilizados para el transporte de personas o bienes, de matrícula o bandera uruguaya, solo podrán asegurarse en empresas instaladas y autorizadas conforme a lo preceptuado en el presente Artículo".

Y finalmente el art 269 de la Ley de la Ley 17.269 de 21/02/2001 (ley de rendición de cuentas) estableció: "Artículo 269.- Sustitúyese el inciso sexto del artículo $2^{\circ}$ de la Ley $N^{o} 16.426$, de 14 de octubre de 1993, en la redacción dada por el artículo $2^{\circ}$ de la Ley $N^{\circ} 16.851$, de 2 de julio de 1997, por el siguiente: Con excepción de los buques mercantes y toda construcción flotante, autopropulsada o no, de carácter civil de bandera nacional, todos los demás vehículos o medios utilizados para el transporte de personas o bienes de matrícula o bandera uruguaya, sólo podrán asegurarse en empresas instaladas y autorizadas conforme a lo preceptuado por el presente artículo. La excepción no comprende a las unidades que integran la flota pesquera".

O sea que en definitiva lo vigente en este tema es:

-Inciso, que ya no es el final, del art 2 de la ley 16.426: Quedan exceptuados de lo dispuesto en el presente articulo los seguros relativos al transporte y comercio internacionales. Con la interpretación de la ley 16. 851, refiere solo a mercancía transportada.

Y el ahora inciso final de art 2 de la ley 16.426: Con excepción de los buques mercantes y toda construcción flotante, autopropulsada o no, de carácter civil de bandera nacional, todos los demás vehículos o medios utilizados para el transporte de personas o bienes de matrícula o bandera uruguaya, sólo podrán asegurarse en empresas instaladas y autorizadas conforme a lo preceptuado por el presente artículo. La excepción no comprende a las unidades que integran la flota pesquera 
En las pólizas emitidas en contravención a lo dispuesto precedentemente, las partes y sus representantes en la operación serán solidariamente responsables por los tributos y sanciones pecuniarias que correspondan.

El artículo maneja el concepto de territorio y a su vez excepciona los seguros enmarcados en acuerdos internacionales.

Respecto a los acuerdos internacionales, en materia marítima no vemos seguros aplicables a las instalaciones offshore, enmarcados en dichos acuerdos, que signifiquen una excepción al artículo 2 de la ley 16.426.

Por el contrario, la normativa sobre seguros contenida en el Tratado de derecho de navegación comercial internacional o tratado de Montevideo de 1940 en su art. 28 establece la aplicación al contrato de seguros de las leyes del Estado sede de la empresa aseguradora. En el caso la ley del estado uruguayo establece que los riesgos que ocurran en el territorio nacional, salvo sus excepciones expresas, deben ser brindados por empresas aseguradoras instaladas en el país. Por lo tanto, nuestra normativa busca aplicar la ley nacional a los seguros.

Asimismo, no existe un instrumento internacional que regule la exploración y explotación de hidrocarburos mar adentro, y aún existe la inquietud sobre la aplicabilidad de los instrumentos internacionales sobre barcos, a las instalaciones oceánicas. ${ }^{?}$

7 Otro punto práctico que dificulta la aplicación de las convenciones marítimas sobre polución aplicables a buques a las instalaciones mar adentro es la limitación de responsabilidad. En la práctica, un barco que transporta hidrocarburos tiene una capacidad máxima que también limita los riesgos, en caso de producirse un derrame. En una plataforma offshore, por su naturaleza, es difícil calcular el riesgo y el costo potencial que podría ocasionar un derrame

Algunos instrumentos internacionales de la OMI, como la Convención Internacional para la Prevención de la Polución por Buques, conocida como MARPOL, capítulo $7^{\circ}$ y las regulaciones 12, 14 y 39 del Anexo 1 podrían utilizarse para regular ciertas características que deben tener las instalaciones oceánicas para limitar riesgos de derrames. En Uruguay, la Ley 14.885 aprueba el Convenio Internacional para Prevenir la Contaminación por los Buques, 1973 y su Protocolo de 1978, MARPOL 73/78, que contiene normas para prevenir la contaminación por Hidrocarburos, Basuras, Aguas Sucias, Mercancías Peligrosas y Sustancias Nocivas Líquidas a Granel.

Por Resolución MEPC. 186(59) del Comité de Protección del Medio Marino de la OMI, adoptada el 17 de julio de 2009, se aprobó en su punto 1 la adición del nuevo Capítulo 8 en el Anexo I del Convenio MARPOL, titulado "Prevención de la Contaminación durante el Trasbordo de Cargas de Hidrocarburos entre Petroleros en el Mar", por el cual se agregan la Regla 40 "Ámbito de aplicación", Regla 41 "Normas generales de seguridad y protección del medio ambiente", y Regla 42 "Notificación", aplicables a los buques petroleros de arqueo bruto igual o superior a 150 Toneladas, excluyendo las operaciones relacionadas con las plataformas fijas o flotantes, las unidades flotantes 
Respecto al territorio, debemos analizar si la plataforma continental es o no territorio del país costeño.

\subsection{El concepto de territorio}

Sabido es que Uruguay ha presentado nuevos estudios del lecho y subsuelo de la plataforma continental, para asegurar la aprobación en la Organización de las Naciones Unidas (ONU) de su pedido de ampliación en el océano Atlántico de 200 a 350 millas náuticas. Muy probablemente el asunto se resolverá positivamente en breve.

La Comisión de Límites de la Plataforma Continental de la ONU recibió de sus especialistas en 2014 la recomendación positiva de habilitar la extensión de la jurisdicción de Uruguay a 350 millas náuticas sobre la plataforma continental del océano Atlántico, al recoger las nuevas investigaciones aportadas por el país.

En agosto del 2015, había acuerdo entre los técnicos con los argumentos y estudios realizados hasta entonces por Uruguay por lo cual la Comisión se proponía elevar una recomendación positiva definitiva al respecto a la Convención de las Naciones Unidas sobre el Derecho del Mar, conocida como CONVEMAR ${ }^{8}$.

de almacenamiento, producción y descarga mar adentro y las operaciones de toma de combustibles.

La Convención Internacional sobre la Contaminación por Hidrocarburos, Preparación, Respuesta y Cooperación de 1990, conocida como OPRC, confirmada por Uruguay, también es útil, pues establece que los operadores de instalaciones mar adentro deben tener planes de contingencia para siniestros de polución en el océano.

Para barcos y buques, la OMI ha desarrollado un régimen muy completo sobre responsabilidad y compensación resultante de los derrames, cuando llevan hidrocarburos como carga o como combustible, que está contenido en la Convención Internacional sobre Responsabilidad Civil por Daños Causados por la Contaminación con Hidrocarburos (CLC 1969), el Protocolo de 1992 a dicha Convención, el Protocolo de 1992 a la Convención Internacional para Establecer un Fondo Internacional de Compensación por los Daños ocasionados por la Polución (FONDO 1992) y la Convención Internacional en Responsabilidad Civil por la Contaminación con Hidrocarburos usados como Combustible de los Buques (Bunkers) 2001. Uruguay ha adherido a los Protocolos de 1992.

8 La Convención de las Naciones Unidas sobre el Derecho del Mar (CDM, o también CONVEMAR o CNUDM) es considerada uno de los tratados multilaterales más importantes de la historia, desde la aprobación de la Carta de las Naciones Unidas, siendo calificada como la Constitución de los océanos. Fue aprobada, tras nueve años de trabajo, el 30 de abril de 1982 en Nueva York (Estados Unidos) y abierta a su firma por parte de los Estados, el 10 de diciembre de 1982, en Bahía Montego (Jamaica), en la 182. ${ }^{\circ}$ sesión plenaria de la III Conferencia de las Naciones Unidas sobre el Derecho del Mar. Entró en vigor el 16 de noviembre de 1994,un año después de la 60. ${ }^{a}$ ratificación (realizada por Guyana). 
Sin embargo, por esos días a Uruguay se le presentó una oportunidad de mejorar el estudio del lecho y subsuelo marítimo, al contar con un barco científico que trabajaba en la zona, que permitió actualizar y aportar nuevos datos a los estudios prospectivos.

A partir de ello solicitó a la Comisión que no elevara la recomendación que estaba planificada para febrero de 2015, sino que esperara los nuevos elementos de estudio.

Uruguay presentó los nuevos datos antes del 10 de julio de 2015, según el plazo que había extendido la Comisión de la ONU.

Sabido es que el territorio marítimo de los estados lo define la CONVEMAR, firmada en 1982 y que entró en vigor el 16 de noviembre de 1994.

La plataforma continental es la base sobre la cual se afirman y asientan los continentes. Es una característica geológica por lo que hay estados que tienen una plataforma continental con extensión limitada, como sucede con los estados del océano Pacífico, mientras que otros tienen una plataforma extensa.

En ese marco, el artículo 76 de la CONVEMAR establece una transacción entre los estados que tienen escasa plataforma continental y los que tienen una extensa, que consiste en que a todos los países, tengan o no geológicamente este accidente geográfico, les corresponderá en principio una zona jurídica propia de 200 millas náuticas o marinas.

Sin embargo, para aquellos estados que naturalmente tienen una plataforma más extensa de las 200 millas, la CONVEMAR estipula que se podrá extender hasta 350 millas, como máximo.

Para ese fin se creó a nivel de la ONU, la Comisión de Límites de la Plataforma Continental, que tiene como fin estudiar los casos y solicitudes presentados por los países que quieran ampliar el límite exterior de su plataforma marítima. ${ }^{9}$

9 La Comisión de Límites está compuesta por 21 miembros, entre los que se cuentan geólogos, geofísicos e hidrólogos, quienes representan a las distintas regiones de los 160 estados que ratificaron la Convención. En ese procedimiento y considerando la geología de Uruguay, fue que el gobierno presentó el 25 de agosto de 2009 la solicitud para extender el límite exterior de su plataforma, la cual 
Los nuevos datos aportados le permitirán a Uruguay confirmar la extensión de su territorio subacuático en más de 81.000 kilómetros cuadrados, sobre los cuales el país tendrá soberanía, veremos más delante de qué tipo y alcance.

Esto es relevante, pues se supone que la humanidad en los próximos años va a funcionar en gran medida con los recursos que tienen las plataformas continentales.

Uruguay cuenta con un reservatorio de bienes, ya sea petróleo, gas, minerales u otros, todos en esa plataforma.

En este mismo sentido, la ONU concedió a Argentina el pedido que presentó para ampliar el límite exterior de su plataforma continental, con lo cual amplió su soberanía.

Tras casi 20 años de trabajo, el pedido argentino fue aprobado el pasado 11 marzo de 2016 por la Comisión de las Naciones Unidas sobre el Derecho del Mar (CONVEMAR). ${ }^{10}$

Brasil atraviesa un proceso similar las de Uruguay y al que recorrió ya Argentina. Por esto cuando Uruguay y Brasil concluyan su trabajo ante la CONVEMAR, el Mercosur habrá generado una ganancia de soberanía y territorio.

comenzó a ser estudiada en 2011 por una subcomisión formada por 7 de los 21 miembros. Desde ese año hasta la fecha hubo al menos 10 reuniones entre la delegación de Uruguay y esa subcomisión. Una vez que la subcomisión eleve a la Comisión el proyecto de recomendación, se espera que la esta emita la recomendación positiva, durante 2016, en la cual se confirmen las condiciones de Uruguay para utilizar su plataforma continental, justificándolo, de acuerdo a los estudios presentados. La recomendación es muy importante, porque le fija a Uruguay un reconocimiento técnico de la ONU para extender a esos puntos el límite exterior de su plataforma. Luego, prosigue el procedimiento interno y, como es un límite, es necesario el dictado de una ley cuyo proyecto debe presentar el Poder Ejecutivo.

10 La superficie comprendida en la demarcación presentada por Argentina, entre las 200 millas marinas y el límite exterior, es de aproximadamente $1.700 .000 \mathrm{~km} 2$, lo que implica un $48 \%$ del territorio emergido de Argentina, a lo que se suman unos $4.800 .000 \mathrm{~km} 2$ comprendidos entre las líneas de base y las 200 millas marinas. Como dijeron las autoridades del vecino país, hay que acostumbrarse a este nuevo mapa, pues hay una Argentina que no vemos y que es casi dos veces la superficie continental. 


\subsection{1. ¿Y qué significa ampliar la plataforma continental?}

Ampliar la plataforma continental supone ampliar los derechos de soberanía del país lo cual tiene implicancias en la cuestión del territorio que analizamos.

Más allá de la teoría de la prolongación y al principio de soberanía a que hemos aludido al inicio de nuestro artículo, lo cierto es que a los países les interesa tener certeza jurídica sobre que podrá realizar actividades económicas en propio beneficio, como el de exploración y explotación offshore, en su plataforma continental. En ese contexto busca extender su soberanía y jurisdicción, veremos en que grado, a toda dicha plataforma, como es el caso antes narrado de Uruguay, o de Argentina.

Por un lado, en razón de los vastos recursos de la plataforma continental sobre los cuales el Estado pasará a tener derechos de soberanía. Por otro, debido a que una delimitación definitiva de nuestra plataforma traerá la seguridad estratégica para la protección y explotación de esos recursos.

Preliminarmente, es necesario aclarar la terminología, pues se suele ser poco precisos en cuanto a los conceptos de mar territorial, zona económica exclusiva y plataforma continental.

En este sentido la CONVEMAR, que es la aplicable al caso, establece que por "Zona" se entiende los fondos marinos y oceánicos y su subsuelo fuera de los límites de la jurisdicción nacional (art.1) y por "actividades en la Zona” se entiende todas las actividades de exploración y explotación de los recursos de la Zona.

Respecto al "Mar territorial", refiere a la franja de mar adyacente al territorio del Estado ribereño, cuya anchura puede ir hasta un límite que no exceda de 12 millas marinas medidas a partir de líneas de base determinadas de conformidad con la Convención (arts 2 y 3 ).

Es importante a nuestros fines, lo establecido por la Convención en cuanto a que la soberanía del Estado ribereño se extiende más allá de su territorio y de sus aguas interiores, al mar territorial. 
Esta soberanía se extiende al espacio aéreo sobre el mar territorial, así como al lecho y al subsuelo de ese mar.

La Zona contigua es aquella que va hasta las 24 millas marinas contadas desde las líneas de base a partir de las cuales se mide la anchura del mar territorial.

En la Zona contigua el Estado ribereño podrá tomar las medidas de fiscalización necesarias para:

a) Prevenir las infracciones de sus leyes y reglamentos aduaneros, fiscales, de inmigración o sanitarios que se cometan en su territorio o en su mar territorial;

b) Sancionar las infracciones de esas leyes y reglamentos cometidas en su territorio o en su mar territorial.

La "Zona económica exclusiva" (en adelante también "ZEE”) es un área situada más allá del mar territorial y adyacente a éste que según la CONVEMAR no se extenderá más allá de 200 millas marinas contadas desde las líneas de base a partir de las cuales se mide la anchura del mar territorial. (art. 57)

Esta zona está sujeta al régimen jurídico específico establecido en la CONVEMAR, de acuerdo con el cual los derechos y la jurisdicción del Estado ribereño y los derechos y libertades de los demás Estados se rigen por las disposiciones pertinentes de la Convención.

En la Zona económica exclusiva, el Estado ribereño tiene: (art. 56)

a) Derechos de soberanía para los fines de exploración y explotación, conservación y administración de los recursos naturales, tanto vivos como no vivos, de las aguas suprayacentes al lecho y del lecho y el subsuelo del mar, y con respecto a otras actividades con miras a la exploración y explotación económicas de la zona, tal como la producción de energía derivada del agua, de las corrientes y de los vientos; 
b) Jurisdicción, con arreglo a las disposiciones pertinentes de esta Convención, con respecto a:

i) El establecimiento y la utilización de islas artificiales, instalaciones y estructuras;

ii) La investigación científica marina;

iii) La protección y preservación del medio marino;

c) Otros derechos y deberes previstos en esta Convención.

En la Zona económica exclusiva, el Estado ribereño tendrá el derecho exclusivo de construir, así como el de autorizar y reglamentar la construcción, operación y utilización de: (art. 60)

a) Islas artificiales;

b) Instalaciones y estructuras para los fines previstos en el artículo 56 y para otras finalidades económicas;

c) Instalaciones y estructuras que puedan interferir el ejercicio de los derechos del Estado ribereño en la zona.

El Estado ribereño tendrá jurisdicción exclusiva sobre dichas islas artificiales, instalaciones y estructuras, incluida la jurisdicción en materia de leyes y reglamentos aduaneros, fiscales, sanitarios, de seguridad y de inmigración.

Respecto a la "plataforma continental" de un Estado ribereño, es la que comprende el lecho y el subsuelo de las áreas submarinas que se extienden más allá de su mar territorial y a todo lo largo de la prolongación natural de su territorio hasta el borde exterior del margen continental, o bien hasta una distancia de 200 millas marinas contadas desde las líneas de base a partir de las cuales se mide la anchura del mar territorial, en los casos en que el borde exterior del margen continental no llegue a esa distancia. (art. 76)

El margen continental comprende la prolongación sumergida de la masa continental del Estado ribereño y está constituido por el lecho 
y el subsuelo de la plataforma, el talud y la emersión continental. No comprende el fondo oceánico profundo con sus crestas oceánicas ni su subsuelo.

Para los efectos de esta Convención, el Estado ribereño establecerá el borde exterior del margen continental, dondequiera que el margen se extienda más allá de 200 millas marinas contadas desde las líneas de base a partir de las cuales se mide la anchura del mar territorial, mediante: (art. 76)

i) Una línea trazada, en relación con los puntos fijos más alejados en cada uno de los cuales el espesor de las rocas sedimentarias sea por lo menos el $1 \%$ de la distancia más corta entre ese punto y el pie del talud continental; o

ii) Una línea trazada, en relación con puntos fijos situados a no más de 60 millas marinas del pie del talud continental.

Estas líneas son líneas rectas, cuya longitud no puede exceder de 60 millas marinas, que unan puntos fijos definidos por medio de coordenadas de latitud y longitud. (párrafo 7 del art. 76).

Salvo prueba en contrario, el pie del talud continental se determinará como el punto de máximo cambio de gradiente en su base.

Los puntos fijos que constituyen la línea del límite exterior de la plataforma continental en el lecho del mar, trazadas de la forma antedicha, deben estar situados a una distancia que no exceda de 350 millas marinas contadas desde las líneas de base a partir de las cuales se mide la anchura del mar territorial o de 100 millas marinas contadas desde la isóbata de 2.500 metros, que es una línea que une profundidades de 2.500 metros. $^{11}$

El Estado ribereño presentará información sobre los límites de la plataforma continental más allá de las 200 millas marinas contadas desde las líneas de base a partir de las cuales se mide la anchura del mar terri-

11 Para fijar el borde exterior del margen continental, Uruguay ha optado por aplicar la "regla Gardiner", que combina la distancia desde el pie del talud con el espesor de las rocas sedimentarias, lo cual fue considerado en su momento un éxito en las negociaciones de parte de Uruguay. 
torial a la Comisión de Límites de la Plataforma Continental, establecida de conformidad con el Anexo II de la Convención, sobre la base de una representación geográfica equitativa. La Comisión hará recomendaciones a los Estados ribereños sobre las cuestiones relacionadas con la determinación de los límites exteriores de su plataforma continental.

Los límites de la plataforma que determine un Estado ribereño tomando como base tales recomendaciones serán definitivos y obligatorios.

El Estado ribereño ejerce derechos de soberanía sobre la plataforma continental a los efectos de su exploración y de la explotación de sus recursos naturales. (art. 77)

Estos derechos son exclusivos en el sentido que, si el Estado ribereño no explora la plataforma continental o no explota los recursos naturales de ésta, nadie podrá emprender estas actividades sin expreso consentimiento de dicho Estado.

Los derechos del Estado ribereño sobre la plataforma continental son independientes de su ocupación real o ficticia, así como de toda declaración expresa.

Los recursos naturales a que refiere son los recursos minerales y otros recursos no vivos del lecho del mar y su subsuelo, así como los organismos vivos pertenecientes a especies sedentarias, es decir, aquellos que en el período de explotación están inmóviles en el lecho del mar o en su subsuelo o sólo pueden moverse en constante contacto físico con el lecho o el subsuelo.

Los derechos del Estado ribereño sobre la plataforma continental no afectan a la condición jurídica de las aguas suprayacentes ni a la del espacio aéreo situado sobre tales aguas.

El antes citado artículo 60 se aplica, mutatis mutandis, a las islas artificiales, instalaciones y estructuras sobre la plataforma continental. (art. 80) 
Figura 3. Zonas maritimas de acuerdo a la CONVEMAR

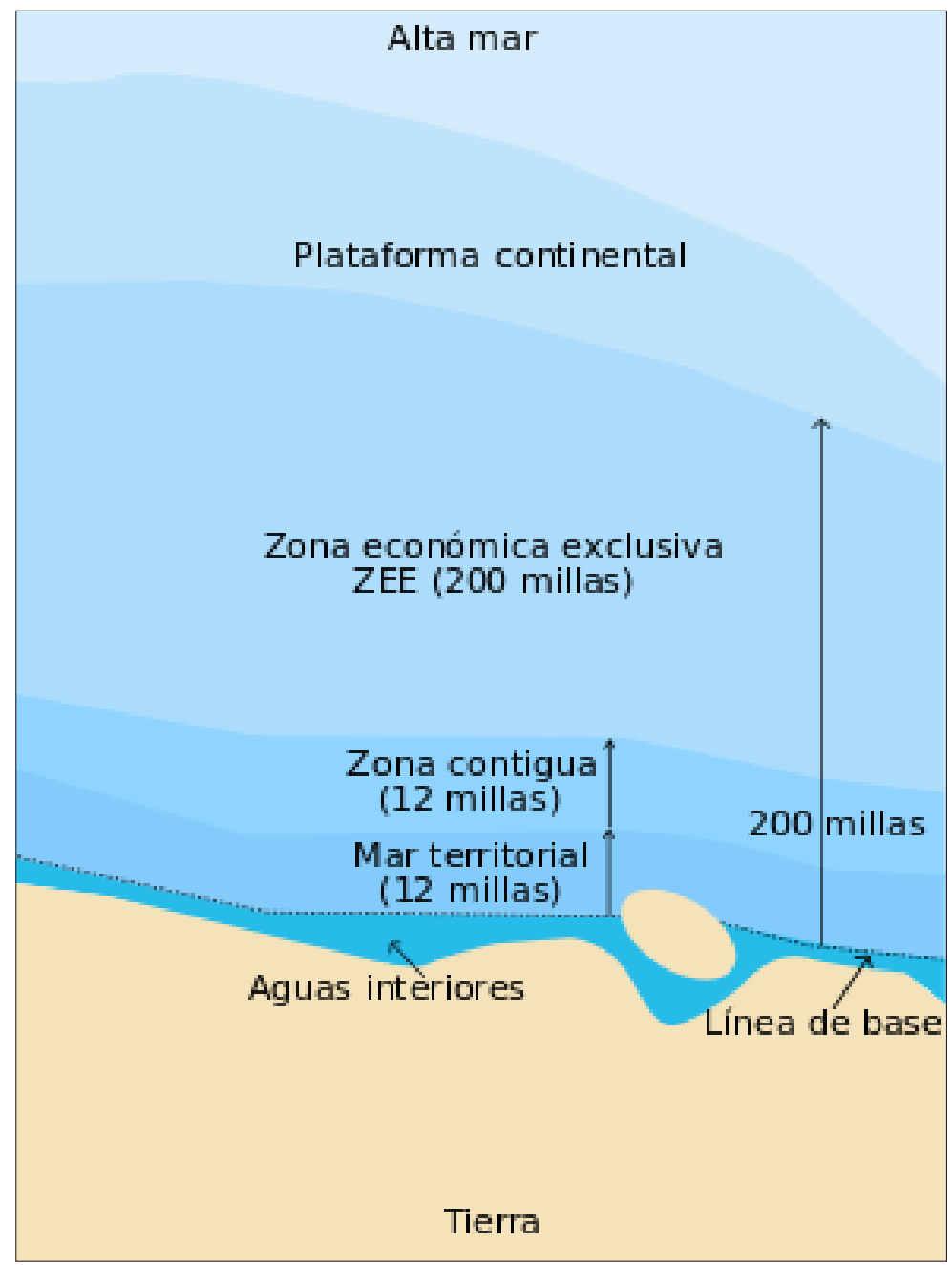

\subsubsection{Concluyendo respecto al territorio}

La CONVEMAR aplica el concepto de soberanía y esto con distintos alcances.

1. Extiende la soberanía del estado ribereño sobre el mar territorial. Esta soberanía se extiende al espacio aéreo sobre el mar territorial, así como al lecho y al subsuelo de ese mar.

2. En la Zona contigua el Estado ribereño podrá tomar las medidas de fiscalización necesarias para: 
a) Prevenir las infracciones de sus leyes y reglamentos aduaneros, fiscales, de inmigración o sanitarios que se cometan en su territorio o en su mar territorial;

b) Sancionar las infracciones de esas leyes y reglamentos cometidas en su territorio o en su mar territorial.

3. En la zona económica exclusiva, el Estado ribereño tiene:

a) Derechos de soberanía para los fines de exploración y explotación, conservación y administración de los recursos naturales, tanto vivos como no vivos, de las aguas suprayacentes al lecho y del lecho y el subsuelo del mar, y con respecto a otras actividades con miras a la exploración y explotación económicas de la zona, tal como la producción de energía derivada del agua, de las corrientes y de los vientos;

b) Jurisdicción, con arreglo a las disposiciones pertinentes de esta Convención, con respecto a:

- La investigación científica marina;

- La protección y preservación del medio marino;

- El establecimiento y la utilización de islas artificiales, instala ciones y estructuras;

Respecto a estas el Estado ribereño tiene el derecho exclusivo de construir, así como el de autorizar y reglamentar la construcción, operación y utilización de:

a) Islas artificiales;

b) Instalaciones y estructuras con finalidades económicas;

c) Instalaciones y estructuras que puedan interferir el ejercicio de los derechos del Estado ribereño en la zona.

El Estado ribereño tiene jurisdicción exclusiva sobre dichas islas artificiales, instalaciones y estructuras, incluida la jurisdicción en materia de leyes y reglamentos aduaneros, fiscales, sanitarios, de seguridad y de inmigración. 
4. En la plataforma continental, el Estado ribereño ejerce derechos de soberanía a los efectos de su exploración y de la explotación de sus recursos naturales.

Los recursos naturales a que refiere son los recursos minerales y otros recursos no vivos del lecho del mar y su subsuelo, así como los organismos vivos pertenecientes a especies sedentarias.

Los derechos del Estado ribereño sobre la plataforma continental no afectan a la condición jurídica de las aguas suprayacentes ni a la del espacio aéreo situado sobre tales aguas.

Respecto a las islas artificiales, instalaciones y estructuras sobre la plataforma continental tiene derechos similares que los establecidos para la zona económica exclusiva.

\subsubsection{Soberania y derechos de soberania sobre el territorio}

Siguiendo al Dr Sergio Abreu ${ }^{12}$, los Estados gozan del atributo de la soberanía sobre su territorio, elemento que explica, por un lado, el funcionamiento de la sociedad internacional, compuesta por Estados igualmente soberanos entre sí y, por el otro, que un Estado ejerza sus competencias en su territorio, con independencia de los demás.

Esto explica que al hablar de "soberanía territorial", se esté indicando el conjunto de competencias de un Estado sobre su espacio físico y que el Derecho Internacional defina al "territorio", como la extensión geográfica sobre la cual se ejerce la autoridad soberana del Estado.

Ahora bien, esta extensión geográfica incluye varios espacios, sobre los cuales el ejercicio de la soberanía estatal es diferente.

1. Existen espacios sobre los cuales se ejerce soberanía absoluta que son:

12 Dr Sergio Abreu en Análisis del CURI, Consejo Uruguayo para las Relaciones Internacionales, 23 de abril de 2015, Análisis No 03/15, "Proyección estratégica del Uruguay en sus espacios marítimos" en www.curi.org.uy/archivos 
- el territorio terrestre, delimitado por los tratados de límites con los Estados fronterizos, que incluye a los ríos, lagos, el suelo y el subsuelo. Este a su vez incluye las aguas subterráneas o acuíferos.

- el territorio marítimo, que incluye las "aguas interiores" y el "mar territorial", espacios donde se ejerce idéntica soberanía absoluta a la que se ejerce sobre el territorio terrestre. ${ }^{13}$

- el espacio aéreo suprayacente a los territorios terrestre y marítimo señalados anteriormente.

La soberanía sobre el espacio aéreo está establecida desde la Convención de París de 1919.

En 1994, con la entrada en vigor de la III CONVEMAR, quedó además claramente definido que dicha soberanía se aplica también sobre las 12 millas de mar territorial que, como vimos, se consideran "territorio marítimo" de los Estados.

2. Existen espacios donde los Estados tienen derechos de Soberanía.

Sobre la Zona Económica Exclusiva y en su Plataforma Continental, los Estados tienen "derechos de soberanía", de naturaleza funcional, en general referidos a su explotación económica, pero no tienen soberanía absoluta sobre los mismos.

Como ya hemos dicho en la Zona económica exclusiva dichos derechos son:

a) Derechos de soberanía para los fines de exploración y explotación, conservación y administración de los recursos naturales, tanto vivos como no vivos, de las aguas suprayacentes al lecho y del lecho y el subsuelo del mar y con respecto a otras actividades con miras a la exploración y explotación económicas de la zona, tal como la producción de energía derivada del agua, de las corrientes y de los vientos;

13 Las "aguas interiores" son las que se encuentran entre la costa y las líneas de base a partir de las cuales se cuentan las demás zonas marítimas. Son por lo tanto, aguas marítimas y no deben confundirse con las "aguas internas" que están totalmente dentro del territorio terrestre y forman parte de éste. El "mar territorial" como vimos se integra con las aguas y el subsuelo costero hasta un máximo de 12 millas marinas, contadas desde las líneas de base trazadas desde la costa. 
b) Jurisdicción, con respecto a: i) El establecimiento y la utilización de islas artificiales, instalaciones y estructuras; ii) La investigación científica marina; iii) La protección y preservación del medio marino;

\section{c) Otros derechos y deberes previstos en la CONVEMAR}

Respecto a la plataforma continental tales derechos de soberanía son similares a los de la ZEE y son a los efectos de la exploración y de la explotación de sus recursos naturales.

La Plataforma Continental comprende el lecho y el subsuelo, no comprende las aguas suprayacentes al suelo. ${ }^{14}$

La mayoría de la doctrina continúa excluyendo a la plataforma continental, de la noción de territorio estatal en sentido estricto, es decir, como el espacio en el que hay soberanía estatal plena.

Sin perjuicio de ello, cabe señalar que la naturaleza jurídica de la plataforma continental tiene algunas peculiaridades jurídicas que incluso la distinguen de la ZEE y la acercan más a las nociones de soberanía plena.

En efecto, la plataforma es considerada "la prolongación natural del territorio terrestre", por lo que si el Estado ribereño no explora la plataforma continental o no explota los recursos naturales de ésta, nadie podrá emprender estas actividades sin expreso consentimiento de dicho Estado. ${ }^{15}$

14 Las reglas relativas a derechos de soberanía y jurisdicción aplicables a dichas aguas serán las correspondientes a la ZEE hasta las 200 millas, y las de alta mar más allá de la milla 200.

15 En este sentido, la Corte Internacional de Justicia ya en el año 1969 en su sentencia en el "Asunto sobre la delimitación de la Plataforma del Mar del Norte", expresó: “ Los derechos de los Estados ribereños sobre su plataforma continental encuentran su fundamento en la soberanía que ejercen sobre su territorio del cual la plataforma es la prolongación natural bajo el mar.'

El fallo añade que aunque están totalmente cubiertas de agua, puede decirse que "esas zonas son una prolongación, una continuación, una extensión de ese territorio debajo del mar

Para la Corte, "los derechos del Estado ribereño... existen ipso facto y ab initio en virtud de su soberanía sobre la tierra y por una extensión de esta soberanía bajo la forma del ejercicio de derechos soberanos a los fines de la explotación de sus recursos naturales "(CIJ). En consecuencia, son derechos exclusivos, y no precisan de declaración expresa por parte del Estado ribereño.

Años más tarde, la CONVEMAR en su el Art. 77.3 confirmaría que "Los derechos del Estado ribereño sobre la plataforma continental son independientes de su ocupación real o ficticia, así como de toda declaración expresa." 
El Dr. Sergio Abreu ${ }^{16}$ señala no obstante que tanto en la Zona económica exclusiva como en la plataforma continental, los terceros Estados conservan algunos derechos, que deben ser concedidos por los Estados ribereños (como por ejemplo, la libre navegación o el derecho a tender cables submarinos en la plataforma continental).

Por esto, el ejercicio de la soberanía estatal sobre estos dos espacios es diferente que en los espacios anteriores de soberanía plena, por lo que se debe ser cuidadoso en la forma de incluir estas dos zonas como parte del territorio, de manera de no contradecir las normas internacionales.

En su concepto, esta inclusión debe hacerse con referencia a los derechos que tiene el Uruguay sobre los mismos, que tengan, a la vez, un componente geográfico y de jurisdicción, de forma que puedan ser considerados como "territorio"

El Dr. Abreu concluye con una definición de territorio nacional que es la siguiente:

"Entiéndese por territorio nacional su territorio terrestre, sus aguas interiores y mar territorial, y el espacio aéreo por encima de los mismos, así como áreas más allá del mar territorial sobre las cuales el Uruguay ejerce derechos de soberanía o jurisdicción de acuerdo con su legislación nacional y el derecho internacional vigente."

A partir de ello, se abre todo un abanico de áreas en las cuales es fundamental si tenemos jurisdicción estatal y qué contenido o alcance tienen los derechos exclusivos de soberanía que se ejercen.

Por ejemplo, recordemos que de acuerdo a la CONVEMAR, sobre las islas artificiales, instalaciones y plataformas que el Estado ribereño tiene el derecho de construir en la ZEE, ese Estado tiene jurisdicción exclusiva, incluida la jurisdicción en materia de leyes y reglamentos aduaneros, fiscales, sanitarios, de seguridad y de inmigración.

Por su parte, el Art. 80 de la CONVEMAR dispone que "el artículo 60 se aplica, mutatis mutandis, a las islas artificiales, instalaciones y estructuras sobre la plataforma continental." En consecuencia, el Estado

16 Dr Sergio Abreu en op.citado. 
ribereño tiene sobre ellas, la misma jurisdicción exclusiva que tiene sobre las que están ubicadas en la ZEE.

\subsection{Concluyendo sobre la reserva de mercado en la plataforma continental}

A la luz del análisis anterior, respecto a la plataforma continental, entendemos que al tratarse de territorio nacional, y sin perjuicio de los diferente grados o derechos de soberanía y jurisdicción, se aplica la regla que los seguros deben ser brindados por empresas aseguradoras debidamente instaladas y autorizadas en el país, con las excepciones que las leyes nacionales establecen para seguros de mercadería trasportadas y buques mercantes, así como toda construcción flotante autopropulsada o no.

Esto implica que los buques mercantes implicados en la operativa pueden tener seguros con empresas no instaladas.

¿Pero que sucede con las plataformas o instalaciones en sí mismas?

Como vimos respecto a instalaciones y estructuras sobre la plataforma continental Uruguay tiene jurisdicción exclusiva, inclusive en materia de seguridad.

En ella Uruguay puede exigir las medidas de seguridad, garantías y entendemos también los seguros que crea necesarios.

Pero la pregunta sigue siendo si estos seguros deben ser brindados por empresas aseguradoras instaladas y autorizadas a operar en Uruguay.

Recordemos que una de las excepciones a la reserva de mercado son las construcciones marítimas autopropulsadas o no. Para esto debemos preguntarnos si el término construcción autopropulsada a que refiere la ley 16.426 puede incluir las plataformas oceánicas.

Esto se relaciona con algunas consideraciones que la doctrina ha realizado sobre la naturaleza de las plataformas.

Primero, ¿son o no son buques? Este punto reviste importancia no solo para los seguros. 
Como ya hemos señalado, no existe un instrumento internacional que regule la exploración y explotación de hidrocarburos mar adentro, y aún existe la inquietud sobre la aplicabilidad de los instrumentos internacionales sobre barcos a las instalaciones oceánicas.

Dado que estas instalaciones pueden variar y algunas pueden transportarse por el mar, podrían ser consideradas barcos. Otras estructuras que se fijan al suelo oceánico parecen islas. Debido a estas características disímiles, es difícil adecuar una de estas estructuras a la definición de un barco en las convenciones marítimas. ${ }^{17}$

17 Siguiendo el excelente artículo del Dr Javier Andrés Franco-Zárate- Universidad Externado de Colombia, revista E-MERCATORIA, Vol. 13, No. 1, enero-junio de 2014 "Alcance del concepto de "nave" en la normatividad mercantil colombiana: ¿incluye dicho concepto el equipo marino utilizado en las operaciones costa afuera (offshore)?" es necesario destacar, que hay muy variados equipos marinos que se utilizan en las operaciones costa afuera u offshore. En efecto, un proyecto de tal naturaleza suele incluir equipos de diferentes características según la labor específica que se requiera ejecutar en cada operación en particular, como ser:

A. Naves de apoyo y/o suministros o genéricamente llamadas "supply vessels": las naves de apoyo son de muy variadas clases y especificaciones según lo requiera la operación. En algunos casos se utilizan remolcadores que apoyan las labores de las plataformas fijas o flotantes. Así mismo, en veces, tales remolcadores son objeto de ciertas modificaciones o adecuaciones menores necesarias para atender los requerimientos operativos del caso (stock de partes, agua y/o suministros, lugares para descanso del personal, etc). En el caso de esta clase de equipos es evidente que se trata de construcciones principales o independientes que son idóneos y están destinados a labores de navegación (bien los buques de apoyo o los de suministros).

B. Unidades móviles (en general): categoría adicional que pretende comprender tanto naves como artefactos navales que tengan una aptitud para ser destinadas específicamente a una actividad, esto es, a labores de exploración y/o explotación de recursos naturales del suelo o subsuelo marinos

Unidad móvil: nave o artefacto naval apto para realizar operaciones destinadas a la exploración y/o a la explotación de recursos naturales del suelo o subsuelo marinos. Puede ser:

- Plataforma de producción, almacenamiento y descarga (IFPAD o FPSO: Floating Production, storage and Offloading ship, por sus siglas en inglés): unidad con forma de buque o barcaza y casco de desplazamiento, ya sea el casco único o múltiple, destinada a operar a flote.

- Plataforma autoelevadora: unidad dotada con dispositivos mecánicos móviles con la capacidad para elevar y hacer descender la plataforma por encima del nivel del mar.

- Plataforma estabilizada por columnas: unidad cuya cubierta principal está conectada a la obra viva o a los pies de soporte por medio de columnas o cajones.

- Plataforma sumergible: toda unidad con forma de buque o de gabarra o con casco de diseño innovador (que no sea autoelevadora), destinada a operar mientras descansa sobre el fondo" (destacado fuera de texto).

Lo cierto es que de acuerdo con la anterior definición de "unidad móvil" se trata en cualquier caso de construcciones flotantes (naves o artefactos navales) aptos para realizar labores de "exploración y/o explotación de recursos naturales del suelo o subsuelo marinos".

Sin perjuicio de la anterior clasificación, vale la pena también hacer un comentario general sobre el tipo de plataformas usualmente empleadas en estas operaciones costa afuera, así:

A. Plataformas flotantes (sin medios propios de propulsión): las plataformas flotantes, bongos, barcazas, u otro tipo de equipos, muchas veces empleados en este tipo de operaciones, equipados, por ejemplo, con equipos de sísmica o perforación, o con dispositivos de almacenamiento y que 
En Inglaterra y otros países, se ha debatido sobre si una plataforma oceánica puede considerarse un barco para efectos de la aplicación de las convenciones sobre hidrocarburos. Por ahora, la posición de la Organización Marítima Internacional (OMI) se inclina a considerar que estas plataformas no son barcos.

Siguiendo esta línea de pensamiento, tales construcciones empleadas en las operaciones costa afuera u offshore estarán por fuera del ámbito de aplicación de las normas tradicionalmente aplicables a los buques mercantes.

Claro que existe una gran variedad de plataformas o instalaciones, para lo cual nos remitimos a nuestra nota al pie número 17. No obstante, nos inclinamos a pensar que la exclusión de la necesidad de tener seguros nacionales aplicable a los buques, no aplica en este sentido a muchos de los tipos antes reseñados de construcciones marítimas o plataformas.

Por esto debemos descartar la exclusión de los buques mercantes y continuar analizando el concepto de construcción flotante autopropulsada o no que menciona la ley 16.426 como otra excepción a la reserva de mercado.

En este sentido, nos inclinamos por considerar que si bien en sentido general podríamos considerar a las plataformas oceánicas como cons-

son usualmente remolcadas a la zona de operación autorizada y desplazados dentro de la misma con apoyo de remolcadores según convenga al desarrollo de la actividad. Estos equipos, pueden ser considerados artefactos navales en tanto se trata de construcciones flotantes que no tienen el carácter de independientes pues para su desplazamiento requieren usualmente el apoyo de remolcadores u otras naves autopropulsadas. B. Plataformas flotantes (con medios propios de propulsión): las plataformas flotantes que tienen medios propios de propulsión generarían alguna discusión respecto de si son naves o artefactos navales. En efecto, cuando el equipo en cuestión tiene la capacidad de desplazarse sobre el agua con sus propios medios, podría pensarse que se trata de una construcción principal e independiente (pues no requiere asistencia para su desplazamiento). Pero, si bien se trata de un equipo marino que eventualmente tiene la capacidad de desplazarse físicamente sobre el agua, sería necesario examinar si se trata de un equipo "destinado habitualmente" a la navegación.

C. Plataformas fijas: las plataformas fijas son también utilizadas en este tipo de operaciones costa afuera y, como su nombre lo indica, son fijadas permanentemente al lecho marino. La pregunta que surge entonces es si puede considerarse que dichas plataformas fijas son, o no, artefactos navales. Al respecto, doctrina foránea ha aclarado ya que "[1] as plataformas fijas o islas artificiales, es decir las construcciones que no se sustentan mediante flotación por estar permanentemente apoyadas en el fondo marino, son bienes inmuebles y no se consideran buques, quedando sometidas a un régimen sui-generis. Este es, particularmente, el caso de las plataformas fijas de perforación y extracción de petróleo y gas". Cfrme Gabaldón García, José Luis. Curso de Derecho Marítimo Internacional, Marcial Pons, Madrid, 2012, p. 380 
trucciones flotantes, el punto es que el artículo 2 de la ley 16.426 que establece la exclusión, debe ser leído en forma contextual.

Dice el inciso final actual de dicho artículo 2: “Con excepción de los buques mercantes y toda construcción flotante, autopropulsada o no, de carácter civil de bandera nacional, todos los demás vehículos o medios utilizados para el transporte de personas o bienes de matrícula o bandera uruguaya, sólo podrán asegurarse en empresas instaladas y autorizadas conforme a lo preceptuado por el presente artículo. La excepción no comprende a las unidades que integran la flota pesquera."

La lectura completa de este inciso deja en claro que refiere a las construcciones flotantes en el contexto de los vehículos o medios utilizados para el transporte de personas o bienes.

Esto hace inútil el debate en cuanto a si dichas construcciones marítimas u oceánicas son o no construcciones flotantes (autopropulsadas o no): si no son utilizadas como medios de transporte no estarán alcanzadas por la exclusión de la reserva de mercado.

\section{LOS SEGUROS EXIGIDOS CONTRACTUALMENTE EN EL MARCO DE LA EXPLORACIÓN Y EXPLOTACIÓN OFFSHORE}

Hemos hecho referencia a los contratos firmados por ANCAP con las empresas interesadas en las actividades de explotación y exploración.

Veamos ahora que dicen esos contratos (modelo aprobado por el Poder Ejecutivo) con respecto a los seguros, en lo esencial (los destacados son nuestros).

\section{“CLÁUSULA $27^{\circ}$ - SEGUROS}

27.1 Los principios que rigen el Contrato respecto a responsabilidad y seguros son los siguientes:

27.1.1 El Contratista y/o el Integrante del Contratista no tendrán ningún tipo de limitación de su responsabilidad respecto a hechos previsibles o imprevisibles, relacionados con los trabajos objeto de este 
Contrato, que puedan generar, en forma directa, indirecta o consecuencial, pérdidas, daños, demoras, detenciones de operación o cualquier alteración, modificación, a los intereses propios, de ANCAP, del Estado Uruguayo o de terceros. Quedan exceptuados los hechos que constituyan un incumplimiento del Contrato y puedan generar, de forma indirecta o consecuencial, pérdidas, daños, demoras, detenciones de operación o cualquier alteración, modificación, que tengan su causa en ANCAP...

En consecuencia deberá prever y asumir la reparación, resolución, o indemnización de toda pérdida o daño que pudiera ocurrir en ocasión de este Contrato.

27.1.2 El Contratista y/o el Integrante del Contratista mantendrá indemne, en forma completa y total, en todo momento y ocasión, a ANCAP de cualquier demanda, reclamo, gasto, o costo relacionado con cualquier tipo de incidente o siniestro que pueda producir los daños o pérdidas ya indicados, sin perjuicio de las obligaciones que le pudieran corresponder a ANCAP como Integrante del Contratista.

27.1.3 El Contratista y/o el Integrante del Contratista deberá tener adecuadamente transferidos los riesgos de sufrir y/o producir daños o pérdidas, que la actividad objeto del presente Contrato pudiere generar. Deberá presentar en forma previa al comienzo de actividades una propuesta documentada de su programa de transferencia de riesgos al Comité de Administración el que aprobará o solicitará los ajustes que correspondan a fin de que, al solo juicio de este último, las previsiones tomadas sean adecuadas a las mejores prácticas de la industria petrolera internacional dentro de las opciones disponibles para cumplir con los principios ya anotados. Este programa se ajustará cada vez que la extensión de las actividades, o la importancia de las mismas se modifiquen, y aun manteniéndose las condiciones de trabajo, el mismo se revisará en una base anual como mínimo.

Ninguna medida de transferencia de riesgos, por ejemplo:

autoseguro, fondo mutuo, utilización de cautiva, o contratación de seguro, liberará al Contratista de sus responsabilidades. Aun contratando seguros, la responsabilidad del Contratista se mantendrá en todo momento o caso intacta, y no podrá solicitar a ANCAP ningún monto 
por concepto de deducibles, franquicias, diferencias de coberturas, diferencias de límites, o exclusiones de los contratos de transferencia de riesgos que haya realizado, o por error en la apreciación o valuación de los riesgos que hubiera asumido, sin perjuicio de las obligaciones que le pudieran corresponder a ANCAP como Integrante del Contratista.

Sin perjuicio de lo ya indicado, en toda transferencia de riesgos por responsabilidades frente a terceros, tanto general de operaciones como ambiental, se deberá incluir a ANCAP como coasegurado y/o asegurado adicional, y la jurisdicción de las mismas deberá ser la de los tribunales de Uruguay. A su vez ANCAP podrá eventualmente y si lo entiende conveniente tomar alguna cobertura de Responsabilidad Civil primaria o de exceso a su cargo, pero, sí esto llegara a ocurrir, en ningún caso podrá ser tomado como liberación de la responsabilidad del Contratista.

27.1.4 En los numerales siguientes se indican los aspectos mínimos a cubrir. El Comité de Administración podrá aceptar variaciones en mérito a solicitud fundamentada del Contratista.

Luego de aceptado el programa de transferencia de riesgos, el Contratista deberá actualizar anualmente el estado del mismo dando prueba de los contratos que se mantienen en vigencia, indicando las aseguradoras y reaseguradoras empleadas; del pago de sus premios en tiempo y forma y del mantenimiento de la confiabilidad de sus aseguradores y reaseguradores en mérito a la opinión de las calificadoras de mayor reconocimiento.

En ningún caso el haber tomado seguros u otras medidas liberará al Contratista de su responsabilidad por las consecuencias derivadas.

Por lo tanto, nunca el Contratista estará liberado de seguir y cumplir con las más estrictas políticas de seguridad de las actividades, procedimientos y de entrenamiento de su personal a fin de prevenir en el mayor grado posible los daños o minimizar su impacto en el caso que algún incidente ocurra.

27.2 El Contratista y Subcontratistas deberán contratar todos los seguros obligatorios que correspondan hoy o puedan corresponder 
en el futuro, de acuerdo a la legislación de Uruguay. En particular, deberá asegurarse todo el personal actuante por accidentes de trabajo en el Banco de Seguros del Estado. El personal extranjero, además de la cobertura que pueda tener en su país de origen, deberá también ser incluido bajo la cobertura del Banco de Seguros del Estado.

27.3 El Contratista y Subcontratistas deberán contar, cada uno de ellos, con un seguro vigente durante todo el periodo del Contrato, que cubra los riesgos operativos de sufrir daños sobre sus activos (bienes, maquinaria, equipos, etc.) requeridos para el cumplimiento del mismo. A su opción podrá también extender la cobertura a cubrir la disminución de ingresos o los costos extraordinarios por la interrupción de su trabajo a causa del siniestro.

27.4 El Contratista deberá contar con una póliza que cubra las pérdidas totales o parciales de Hidrocarburos, a valor de reposición del producto perdido y con deducible máximo del diezpor ciento (10\%) del monto a riesgo, desde su extracción (boca de pozo) hasta el momento en que ANCAP o quien corresponda, tomen posesión y control del mismo (punto de fiscalización).

27.5 El Contratista deberá tener y mantener en vigencia una póliza que cubra su Responsabilidad Civil ("RC") de Operaciones y la de sus Subcontratistas hacia terceros por daños a personas y/o bienes, por un valor que deberá guardar relación con el valor promedio que rija internacionalmente para coberturas similares, sin perjuicio de cubrir con holgura la estimación más pesimista de daños en un incidente o grupo de incidentes, que tendrá un límite no menor de cien millones de Dólares (100.000.000 US\$) para todos ellos en conjunto o por separado (RC Cruzada), y un deducible no mayor del dos por ciento (2\%) del límite de indemnización. Tanto el Contratista como cada uno de los Subcontratistas deberá contar a su vez con las pólizas especificas que correspondan a cada actividad, y que mantengan en su cobertura, límite y deducible una adecuada relación con la póliza principal, dependiendo de la participación en el Contrato y de la importancia y particularidad de los equipos involucrados (P\&I para buques, $R C$ transportistas para camiones, $R C$ de aviación, etc.) las que deberán cumplir con las disposiciones legales del Uruguay. 
27.6 El Contratista deberá tener y mantener en vigencia una póliza que cubra su Responsabilidad Civily la de sus Subcontratistas por daños al medio ambiente, por un valor que deberá guardar relación con el valor promedio que rija internacionalmente para coberturas similares, sin perjuicio de cubrir con holgura la estimación más pesimista de daños de esta categoría en un incidente o grupo de incidentes, y que tendrá un límite no menor de cien millones de Dólares (100.000.000 US\$) para el período de exploración y no menor de dos cientos millones de Dólares (200.000.000 US\$) para el período de explotación, y un deducible no mayor del dos por ciento (2\%) del límite de indemnización en cada caso. Toda el Área deberá estar cubierta por el o los seguros contratados, o por la pertenencia a fondos de reparo especialmente previstos para este tipo de contingencias. En particular, deberán estar cubiertos: Plataformas; buques de apoyo; buques tanqueros; ductos y almacenamiento de Hidrocarburos, etc.

Se cubrirán los daños por contaminación y/o filtración por cualquier causa accidental, súbita e imprevista, durante las operaciones, en conjunto con la póliza de RC General indicada anteriormente o por separado, por medio del programa de coberturas que el Contratista proponga y que el Comité de Administración acepte como válido, teniendo en cuenta los valores señalados como mínimos a cumplir.

27.7 Los montos mínimos de cobertura establecidos en los numerales 27.5 y 27.6 podrán ser revisados por el Comité de Administración, según necesidades.

Analizando el clausulado contractual, no sólo este artículo 27, podemos resumir en tres puntos la temática:

\subsection{Responsabilidad del contratista y subcontratista}

Es claro que la responsabilidad en cabeza del contratista, hacia ANCAP así como hacia otros terceros, es amplia e ilimitada en la letra del contrato.

Esto esencialmente en base a las obligaciones que asume el Contratista en especial en el artículo $6^{\circ}$, subnumerales 6.2.7- que consagra una responsabilidad residual y general, 6.2.12- que prevé acciones ante 
contaminación ambiental; 6-2.24 por accidentes de trabajo, 6.2.33, que prevé también en forma general la liberalización o indemnización de ANCAP ante toda reclamación de terceros. ${ }^{18}$

Asimismo, vemos reiterado en todo el contrato el enfoque hacia la responsabilidad total y sin límites del contratista por las obligaciones asumidas y por los daños que pueda provocar su actuar en el marco del contrato, incluso ante causas previsibles e imprevisibles.

Del punto de vista del seguro, el aspecto a analizar aquí es si esa responsabilidad ilimitada es pasible de ser cubierta eficazmente.

La respuesta viene de la mano de unos de los factores o caracteres que hacen que un riesgo sea asegurable, que es que el mismo debe ser medible, tasable, dimensionable.

El seguro debe tener una limitación cierta del riesgo a asumir, la cual se suele determinar a través de la suma total asegurada, el empleo de las cláusulas claims made y el empleo de franquicias deducibles.

Respecto a las cláusulas claims made, se suelen utilizar en los seguros de responsabilidad civil en los cuales la prescripción de los reclamos o la vigencia de la responsabilidad en cabeza del causante del daño, son de cola larga o long tail. Ante esto el asegurador debe limitar el plazo durante el cual pueden presentarse reclamos, los cuales en virtud de esta cláusula solo pueden referirse a actos dañosos ocurridos durante la vigencia de la póliza y deben presentarse ya sea durante la misma vigencia o durante el plazo posterior a esta fijado en la póliza, llamado plazo de descubrimiento, o ex post o adicional por reclamos, o extendido.

El factor medibilidad del riesgo es uno de los factores que hace que por ejemplo, el seguro ambiental sea uno de los más difíciles de implementar, como veremos seguidamente al hablar brevemente de los seguros exigidos.

18 6.2.7 Asumir, en forma exclusiva y total, la responsabilidad por todos y cualesquiera daños y perjuicios causados por él, su personal o sus Subcontratistas 6.2.12 Tomar todas las acciones pertinentes en las situaciones de emergencia y Causa Extraña No Imputable. En particular y sin que tenga carácter taxativo, realizar todas las tareas necesarias para, en caso de contaminación, limpiar y descontaminar las aguas, las costas, las playas y cualquier otro territorio. 6.2.33 Liberar e indemnizar a ANCAP, según corresponda, de cualquier reclamación, acción legal y otros cargos de terceros que pudieran resultar perjudicados como consecuencia de las actividades del Contratista y sus Subcontratistas. Los gastos en que incurra el Contratista por estos conceptos no serán considerados Cost Oil. 
Es por esta responsabilidad ilimitada en cabeza del contratista, que el contrato analizado habla de "transferencia de riesgos" la cual puede realizarse por diversos medios, no solo a través de los seguros.

Se menciona en el artículo 27 como ejemplos de transferencia de riesgos al autoseguro, al fondo mutuo, la utilización de cautiva, o la contratación de seguro.

Respecto a estos medios de transferencia de riesgos antes que nada debemos tener en cuenta lo que hemos referido respecto a la reserva de mercado en Uruguay. Salvo acuerdos internacionales como ser los que imponen fondos para riesgos de contaminación, debemos tener presente que nuestra legislación en seguros exige que los riesgos que acaezcan en el territorio nacional sean cubiertos por empresas aseguradoras debidamente instaladas y autorizadas.

Nos hemos referido extensamente al concepto de territorio. Aquí solo señalar que el autoseguro no es un concepto afín a nuestra legislación en seguros que no admite la existencia de mutuas de seguros (salvo las ya existentes desde antes de la desmonopolización) ni el autoseguro, sino que los seguros deben ser brindados por empresas aseguradoras constituidas como sociedades anónimas uruguayas. El propio artículo 27 analizado establece que los seguros deben cumplir con las disposiciones nacionales.

En líneas generales ambos tipos de seguros son seguros cubiertos por los propios asegurados, sin las bases técnicas de las empresas aseguradoras.

Claro que no podemos desconocer la importancia del sistema mutual en materia marítima, si pensamos en los Clubes de protección e indemnidad (P\&I), uno de los más exitosos sistemas mutuales de cobertura de riesgos marítimos, especialmente los de contaminación, a nivel internacional.

Pero lo cierto es que salvo las expresas menciones a los P\&I que citamos a continuación, nuestra legislación actual en seguros no menciona esta posibilidad, aspecto que deberá tenerse en cuenta sin dudas si pensamos en una legislación específica para las actividades de exploración 
y explotación, como es el caso actualmente en Uruguay donde el tema de legislar está presente.

Dichas menciones a los P\&I son:

- la referida a las garantías de los Clubes en materia de embargo y secuestros de buques que contiene nuestra reciente legislación de derecho marítimo (ley 19.246 de 15 agosto 2014) y

- la Disposición marítima 141 de la Prefectura nacional naval, que actualiza las "Normas para prevenir la contaminación por buques petroleros que realicen operaciones de transbordo de hidrocarburos buque a buque en la zona económica exclusiva", que refiere a la exigencia de que dichos buques, en las operaciones de transbordo de hidrocarburos, además de contar con cobertura por el Convenio Internacional sobre Responsabilidad Civil por Daños Causados por la Contaminación de las Aguas del Mar por Hidrocarburos, 1969 en su forma enmendada (CLC, International Convention on Civil Liability for Oil Poliution Damage) que cubra los posibles daños que puedan producirse y las operaciones de recuperación, deberán poseer un seguro de Protección e Indemnización de primer nivel por un monto equivalente (o superior) a U\$S 1.000.000.000 (mil millones de dólares americanos) con igual propósito.

Similar apreciación aplica a la mención al uso de cautivas, lo cual ciertamente refiere al uso de instrumentos alternativos de Riesgos, conocidos como ART por sus siglas en inglés, los cuales operan como formas especiales de reaseguros financieros y cuya profundización escapa al alcance de este artículo. ${ }^{19}$

Respecto a la transferencia de riesgos a través de los seguros, es claro que esto incluye la contratación de seguros y también de reaseguros ya sea mediante la tradicional cesión de parte de los riesgos de la aseguradora al reasegurador, o bien mediante la modalidad, admitida en nuestro país, de fronting, es decir la emisión de la póliza por la empresa nacional, autorizada pero con transferencia del $100 \%$ del riesgo a un reasegurador de

19 Para profundizar en estos métodos alternativos de transferencia de riesgos y reaseguros financieros, nos remitimos a nuestro artículo contenido en nuestra reciente obra "Estudios de Derecho de Seguros y Reaseguros" editorial La Ley, agosto de 2016. 
primera línea con sede en el exterior. Este último mecanismo, si bien ha recibido críticas de reconocida doctrina en derecho de seguros, como es el caso del Dr Ruben Stiglitz de Argentina ${ }^{20}$, es admitido pacíficamente en nuestro país y resulta esencial para la asunción de grandes riesgos como son los que se asumen en la rama marítima.

En este punto pues, entendemos que el Comité de Administración previsto en los contratos referidos, en su momento deberá evaluar el mecanismo de transferencia de riesgos propuesto por el Contratista y que el mismo sea acorde con la legislación en seguros vigente en el país.

\subsection{Aspectos preventivos}

Se ha destacado suficientemente el factor preventivo a lo largo del contrato en especial en el antedicho artículo $6^{\circ}$, subnumeral 6.2.8, que consagra la prevención con carácter general, 6.2.9, prevención contra daños a la navegación y pesca, 6.2 .10 prevención medioambiental incluyendo acuática, atmosférica, terrestre. 6.2.11., contaminación marina, entre otros artículos en igual sentido de destacar la prevención. ${ }^{21}$

Del punto de vista del seguro, la prevención en este tipo de riesgos es esencial y el factor clave de la utilidad de la cobertura aseguraticia como veremos seguidamente.

Esto pues por más que nos esforcemos en consagrar la responsabilidad ilimitada del contratista, con fórmulas genéricamente amplias, en caso, por ejemplo, de desastre ambiental, difícilmente podamos recurrir

20 Dr Ruben Stiglitz "La distorsión del reaseguros. El fronting” Temas de derecho de seguros, Colección internacional Universidad javeriana de Colombia, págs 277 y sgts.

21 6.2.8 Adoptar medidas preventivas de seguridad respecto al personal, las instalaciones, los equipos y vehículos que utilice, incluyendo los de los Subcontratistas.

6.2.9 El Contratista se ajustará a lo dispuesto en las leyes de la República Oriental del Uruguay relativas a navegación marítima y áreas vinculadas con las Operaciones Petroleras. A tales efectos, habrá de emplear medios adecuados para minimizar los inconvenientes que su actividad pudiere irrogar a la navegación y a la pesca.

6.2.10 Adoptar las medidas apropiadas para evitar vertimientos de Hidrocarburos o sus derivados o toda otra sustancia que pueda contaminar o ensuciar las aguas, las costas, las playas y cualquier territorio. Asimismo adoptará todas las medidas apropiadas para mitigar la contaminación atmosférica.

6.2.11 Cumplir todas las normas internas de la República Oriental del Uruguay, Tratados y Convenios Internacionales sobre protección del medio ambiente, especialmente en lo que hace a contaminación de los mares y aguas. 
al seguro o a otra forma de transferencia de riesgos como medida de solución ya que solamente podrán brindar paliativos, nunca la transferencia del riesgo será suficientemente indemnizatoria ni reparadora o recomponedora del daño ocasionado. Lo mismo aplica a otros daños catastróficos ya sea humanos u operativos.

Por lo tanto, destaco la función (y desafío) del Comité de administración en el sentido de la debida evaluación de las medidas preventivas que el contratista asuma.

En ambos temas pues, creo clave la necesaria especialización técnica y específica del Comité de Administración, o de sus asesores, para las diversas funciones asumidas en el contexto de este contrato.

\subsection{Tipos de Seguros}

El artículo 27 es muy amplio en las coberturas exigidas, en la misma línea del punto 1 anterior y destacando la total responsabilidad del contratista y la total indemnidad de ANCAP.

Se exigen coberturas de todo riesgo operativo, lo cual suele ser una diversidad de coberturas que abarca seguros de daño, como los que se menciona de los buques, maquinarias, equipos, que pueden a su vez causar incumplimientos contractuales, que podrían ser cubiertos mediante seguros de cumplimiento, y seguros de responsabilidad civil por daños a terceros durante la operativa del Contratista y subcontratistas.

Se puede asimismo cubrir la disminución de ingresos o los costos extraordinarios por la interrupción del trabajo a causa del siniestro, lo cual en general se adiciona a la cobertura principal de daño o responsabilidad civil.

La cláusula 27 exige asimismo una póliza que cubra las pérdidas totales o parciales de Hidrocarburos, a valor de reposición del producto perdido y con deducible máximo del diez por ciento (10\%) del monto a riesgo, desde su extracción (boca de pozo) hasta el momento en que ANCAP o quien corresponda, tomen posesión y control del mismo (punto de fiscalización). 
Se exigen asimismo todos los Seguros obligatorios: refiere solo al de accidentes de trabajo pero entiendo que al decir "todos" incluye el Seguro obligatorio Automotor para el caso de vehículos asociados a la operación offshore, que se desplacen por el territorio nacional.

Respecto a los seguros de responsabilidad civil, emergente de las Operaciones del Contratista y las de sus Subcontratistas por daños a personas y/o bienes de terceros, la cláusula $27, .5$ exige un seguro por un valor que deberá guardar relación con el valor promedio que rija internacionalmente para coberturas similares, "sin perjuicio de cubrir con holgura la estimación más pesimista de daños en un incidente o grupo de incidentes, que tendrá un límite no menor de cien millones de Dólares (100.000.000 US\$) para todos ellos en conjunto o por separado .... y un deducible no mayor del dos por ciento (2\%) del límite de indemnización.'

Se aclara que tanto el Contratista como cada uno de los Subcontratistas deberá contar a su vez con las pólizas específicas que correspondan a cada actividad, y que mantengan en su cobertura, límite y deducible una adecuada relación con la póliza principal, dependiendo de la participación en el Contrato y de la importancia y particularidad de los equipos involucrados (P\&I para buques, RC transportistas para camiones, RC de aviación, etc.) las que deberán cumplir con las disposiciones legales del Uruguay.

Si bien el contrato en otro punto habla de la no posibilidad de existencia de deducibles a cargo de ANCAP, aquí si lo señala tal vez consciente que sin este tipo de limitaciones difícilmente resulten ser riesgos asegurables, o para los cuales se puedan conseguir coberturas, como ya hemos mencionado.

Resulta interesante asimismo, los montos de cobertura que se manejan en el artículo, ya que la paramétrica de los seguros, dado el riesgo involucrado, no es fácil de establecer y es óptimo que esté dada de antemano. De todas formas, la cláusula, como vimos, consagra la responsabilidad del contratista más allá de las coberturas de seguros u otras con que cuente.

Respecto finalmente a los seguros ambientales la cláusula 27.6 establece que el Contratista deberá tener y mantener en vigencia una póliza 
que cubra su Responsabilidad Civil y la de sus Subcontratistas por daños al medio ambiente, por un valor que deberá guardar relación con el valor promedio que rija internacionalmente para coberturas similares, "sin perjuicio de cubrir con holgura la estimación más pesimista de daños de esta categoría en un incidente o grupo de incidentes, y que tendrá un límite no menor de cien millones de Dólares (100.000.000 US\$) para el período de exploración y no menor de dos cientos millones de Dólares (200.000.000 US\$) para el período de explotación, y un deducible no mayor del dos por ciento ( $2 \%$ ) del límite de indemnización en cada caso".

Toda el Área deberá estar cubierta por el o los seguros contratados, o por la pertenencia a fondos de reparo especialmente previstos para este tipo de contingencias. En particular, deberán estar cubiertos: Plataformas; buques de apoyo; buques tanqueros; ductos y almacenamiento de Hidrocarburos, etc.

Se cubrirán los daños por contaminación y/o filtración por cualquier causa accidental, súbita e imprevista, durante las operaciones, en conjunto con la póliza de Responsabilidad general indicada en el 27.5 o por separado.

Cabe destacar la exigencia de seguros de Responsabilidad civil para los riesgos ambientales, y no otro tipo de coberturas como las de caución que no aportan los necesarios aspectos preventivos que si aportan los seguros de Responsabilidad civil en materia ambiental.

Es que del punto de vista del seguro, en materia de explotaciones o emprendimientos de alta exposición al riesgo o de difícil tasabilidad del riesgo, caso típico el riesgo medioambiental, máxime con hidrocarburos involucrados, lo esencial es la prevención.

En los seguros de Responsabilidad civil el asegurador realiza una tarea de prevención junto con la empresa aseguradora, procurando minimizar los riesgos, lo cual no existe en los seguros de caución que operan como simples garantías o "avales".

En vistas a la correcta cobertura, los Seguros de responsabilidad civil deben tener limitaciones, como hemos visto, que hagan que los riesgos puedan ser dimensionados y por ende cubiertos. Deberán ser seguros con sumas aseguradas claras, con coberturas de tipo claims 
made y ciertamente exigirán deducibles (montos o porcentajes a cargo del asegurado) para fomentar la debida diligencia del asegurado en el manejo de los riesgos.

Esto pues son notorias las dificultades que existen a nivel mundial para la implementación de los "seguros ambientales" lo cual ha llevado a la creación fondos de garantías que tratan de resolver esto problemas.

Es así que en muchos países las aseguradoras son reticentes a cubrir estos riesgos, ya que el riesgo asegurable presenta algunos problemas comunes, de difícil resolución.

Por un lado, existe una dificultad técnica para determinar la tasa de siniestralidad. En materia ambiental faltan elementos de referencia fiables ya que el riesgo de contaminación ha aparecido tradicionalmente unido a otros riesgos (daños y Responsabilidad Civil), sin que se haya identificado como tal riesgo autónomo.

Otro aspectos importantes del seguro ambiental, que lo distingue de los demás seguros, es la excesiva incertidumbre que puede traer el daño ecológico. Así el sistema asegurador diferencia el daño que irrumpe accidentalmente, del daño continuo y permanente que debería ser conocido por parte de la empresa. ${ }^{22}$

Otra dificultad surge con la contaminación gradual, ya que debe determinarse desde qué momento comienza a producirse el daño, para determinar a partir de cuándo cabe la responsabilidad del asegurador, con la dificultad adicional de que se suele exigir que sea la manifestación inicial del daño la que deba ocurrir durante la vigencia de la póliza (además del reclamo en las pólizas de tipo Claims Made) para estar cubierto por el seguro.

22 La doctrina ambientalista diferencia tipos de daño ambiental que suele dividirse en: - daño ambiental civil o Indirecto;-daño ambiental colectivo o Directo

El daño ambiental civil es aquel que sufre una persona sobre si misma, o sobre sus bienes patrimoniales a través de un elemento del ambiente. Se lo llama también Indirecto porque supone la preexistencia de un daño directo sobre algún elemento del ambiente.

En general, para estos supuestos se prevé la indemnización o reparación civil en dinero o en especie. El daño ambiental colectivo en cambio, es aquel que ocurre sobre algún elemento del ambiente con prescindencia de que éste se traduzca en un daño sobre una persona o sus bienes, es por ello que se lo llama directo.

Este daño a un bien público, como es el ambiente en conjunto o cualquiera de sus elementos, genera en general una obligación, en muchas legislaciones de rango constitucional, prioritaria de recomponer. 
Por último, resulta además extraordinariamente complicada la evaluación financiera de los daños derivados de la realización del siniestro, y muchas veces la magnitud del siniestro es tal que escapa a la propia capacidad financiera de las aseguradoras, lo que conlleva a las mismas a retirarse del mercado o establecer primas sumamente elevadas, imposibilitando a las empresas de menor tamaño poder obtener dicha cobertura.

Por eso la labor preventiva, la exigencia de requisitos de asegurabilidad que aportan los seguros de responsabilidad civil, con la debida delimitación del riesgo son la respuesta, siempre parcial por lo que ya hemos indicado en puntos anteriores, que el seguro puede dar a este tipo de riesgos, sin perjuicio de la utilización de fondos si estos son debidamente organizados, administrados y por supuesto amparados por la legislación nacional.

\section{CONCLUSIONES}

La problemática sobre los seguros en el marco de las actividades de exploración y explotación off shore o costa afuera, excede lo que puede incluirse en un artículo doctrinario.

Mucho más habría que decir sobre el alcance de la reserva de mercado en materia aseguradora, sobre la cuestión de si las plataformas o construcciones marítimas en el marco de ellas son o no buques, mucho más para decir sobre las Convenciones internacionales sobre Contaminación que Uruguay no ha aprobado, más sobre los tipos de contratos exigidos en el marco de los contratos de exploración y explotación, y los que pueden exigirse, pudiendo analizarse cada tipo de seguros en forma puntual.

Lo que a nuestros efectos hemos tratado con este artículo es de aproximarnos en forma general al tema, intentando despejar algunas dudas sobre un tema que está lejos de ser superficial, dado los riesgos implicados en estas actividades y reviste un interés doctrinario general en vistas al auge de este tipo de emprendimientos económicos a nivel no solo nacional, sino regional y mundial.

Nos queda pues planteado, el seguir analizando la temática en futuros artículos. 


\section{BIBLIOGRAFÍA}

Abreu, Sergio “Análisis del CURI, Consejo Uruguayo para las Relaciones Internacionales, 23 de abril de 2015, Análisis No 03/15, "Proyección estratégica del Uruguay en sus espacios marítimos" eww.curi.org.uy/archivos-recuperado julio 2016.

Franco-Zárate, Javier Andrés- "Alcance del concepto de "nave" en la normatividad mercantil colombiana: ¿incluye dicho concepto el equipo marino utilizado en las operaciones costa afuera (offshore)? Universidad Externado de Colombia, revista E-MERCATORIA, Vol. 13, No. 1, enero-junio de 2014

Rodríguez, LIiana "Aspectos legales de la exploración de hidrocarburos mar adentro" 12/03/2014 www.rodriguezretamoso.co.uk - recuperado julio 2016.

Signorino, Andrea "Estudios de Derecho de Seguros y Reaseguros” Editorial La Ley, septiembre de 2016.

Stiglitz, Ruben "La distorsión del reaseguros. El fronting" Temas de derecho de seguros, Colección internacional -Universidad javeriana de Colombia, editorial Ibañez, 2010.

Truman, Harry- Proclamación Presidencial de los EE UU No 2667, política de los EE UU con relación a los recursos naturales en el subsuelo y la placa continental, Washington, 28 de septiembre de 1945.

\section{Convenciones}

Convención de las Naciones Unidas sobre el Derecho del Mar (CDM, CONVEMAR o CNUDM), 1994.

Convenio Internacional para Prevenir la Contaminación por los Buques, 1973 y su Protocolo de 1978, MARPOL 73/78.

Convención Internacional sobre la Contaminación por Hidrocarburos, Preparación, Respuesta y Cooperación de 1990, OPRC,

Convención Internacional sobre Responsabilidad Civil por Daños Causados por la Contaminación con Hidrocarburos (CLC 1969), y Protocolo de 1992

Convención Internacional para Establecer un Fondo Internacional de Compensación por los Daños ocasionados por la Polución (FONDO 1992) y Protocolo de 1992.

Convención Internacional en Responsabilidad Civil por la Contaminación con Hidrocarburos usados como Combustible de los Buques (Bunkers) 2001. 


\section{Leyes}

Ley 16.426, octubre de 1993.

Ley 16.851, julio de 1997,

Ley 17.269, febrero de 2001

\section{Decretos y Resoluciones}

Decreto del Poder Ejecutivo N³16/2011 “Bases Para la Selección de Empresas Petroleras para la Exploración y Explotación de Hidrocarburos en Costa Afuera de la República Oriental del Uruguay (Ronda Uruguay II)"

Resolución sin número del Ministerio de Industria, Energía y Minería- publicada en el Diario oficial el 17 de setiembre de 2012 "Modelo de Contrato para el Otorgamiento de Áreas para la Exploración - Explotación de Hidrocarburos en Costa Afuera de la República Oriental del Uruguay"

\section{Jurisprudencia}

Decisión de la Corte Internacional de Justicia, en la Sentencia sobre la Placa Continental del Mar del Norte. (North Sea Continental Shelf, Judgment, I.C.J. Reports 1969, p. 3). 
